\title{
Effects of levothyroxine treatment on pregnancy outcomes in pregnant women with autoimmune thyroid disease
}

\author{
Sima Nazarpour1,3, Fahimeh Ramezani Tehrani², Masoumeh Simbar ${ }^{3}$, \\ Maryam Tohidi ${ }^{4}$, Hamid Alavi Majd ${ }^{5}$ and Fereidoun Azizi ${ }^{6}$
}

'Department of Midwifery, Faculty of Nursing and Midwifery, Islamic Azad University, Varamin-Pishva Branch, ${ }^{2}$ Reproductive Endocrinology Research Center, Research Institute for Endocrine Sciences, ${ }^{3}$ Department of Reproductive Health and Midwifery, Faculty of Nursing and Midwifery, ${ }^{4}$ Prevention of Metabolic Disorders Research Center, Research Institute for Endocrine Sciences, ${ }^{5}$ Department of Biostatistics, Faculty of Paramedicine, and ${ }^{6}$ Endocrine Research Center, Research Institute for Endocrine Sciences, Shahid Beheshti University of Medical Sciences and Health Services, Tehran, Iran

Correspondence should be addressed to F Ramezani Tehrani Email

ramezani@endocrine.ac.ir or framezan@post.harvard.edu

\begin{abstract}
Background: Despite some studies indicating that thyroid antibody positivity during pregnancy has been associated with adverse pregnancy outcomes, evidence regarding the effects of levothyroxine (LT4) treatment of euthyroid/ subclinical hypothyroid pregnant women with autoimmune thyroid disease on pregnancy outcome is limited. We aimed to assess whether pregnant women with autoimmune thyroid disease, but without overt thyroid dysfunction are affected by higher rates of adverse pregnancy outcomes. In addition, we aimed to explore whether LT4 treatment improves the pregnancy outcome of affected women.

Methods: A prospective study was carried out on pregnant women from the first trimester to delivery. The study was conducted among pregnant women receiving prenatal care in centers under coverage of Shahid Beheshti University of Medical Sciences. Of a total of 1746 pregnant women, screened for thyroid dysfunction, 1028 euthyroid TPOAbnegative (TPOAb-) and 131 thyroid peroxidase antibody-positive (TPOAb ${ }^{+}$) women without overt thyroid dysfunction entered the second phase of the study. TPOAb ${ }^{+}$women were randomly divided into two groups: group $A(n=65)$, treated with LT4 and group B ( $n=66)$, received no treatment. The $1028 \mathrm{TPOAb}^{-}$women (group C) served as a normal population control group. Primary outcomes were preterm delivery and miscarriage and secondary outcomes included placenta abruption, still birth, neonatal admission and neonatal TSH levels.

Results: Groups A and C displayed a lower rate of preterm deliveries compared with group B (RR=0.30, 95\% Cl: 0.1-0.85, $P=0.0229)$ and ( $R R=0.23,95 \% \mathrm{Cl}: 0.14-0.40, P<0.001)$ respectively. There was no statistically significant difference in the rates of preterm labor between groups $A$ and $C(R R=0.79,95 \% \mathrm{Cl}: 0.30-2.09, P=0.64)$. The number needed to treat (NNT) for preterm birth was 5.9 (95\% Cl: 3.33-25.16).

Conclusions: Treatment with LT4 decreases the risk of preterm delivery in women who are positive for TPOAb.
\end{abstract}

\section{Introduction}

Thyroid disorders, especially those of autoimmune origin, are common in women of reproductive age $(1,2)$. Although the complications of overt hypothyroidism or
() 2017 European Society of Endocrinology Printed in Great Britain hyperthyroidism on pregnancy outcomes, and neonatal and childhood development are well known (3), there is still no consensus on the association between subclinical 
thyroid disorders or autoimmune thyroid disorders and complications in pregnancy and childhood. Some studies have shown that subclinical hypothyroidism and thyroid autoimmunity are associated with a higher rate of placental abruption, preterm birth, miscarriage, gestational hypertension, fetal distress, severe preeclampsia, neonatal distress and gestational diabetes $(4,5,6,7)$, whereas others document controversial findings $(8,9,10)$. A meta-analysis conducted by Sheehan et al. demonstrated no significant increase in odds ratio of preterm labor in women with subclinical hypothyroidism and isolated hypothyroxinemia (11), whereas Chan et al. reported a pooled odds ratio of 1.93 (1.40-2.64) for pregnancy loss, which included miscarriages, stillbirths and perinatal losses up till the first week of life (10).

A number of observational studies have reported that euthyroid TPO antibody-positive women are at increased risk of adverse outcomes of pregnancy such as miscarriage and premature labor or even neonatal complications (12, $13,14)$; however, others found no association $(9,15,16)$.

Despite the influence of thyroid autoimmunity reported in observational studies, even among euthyroid/subclinical hypothyroid pregnant women, there are limited trials on thyroxine supplements having beneficial effects on prenatal outcomes in this group $(17,18)$. As a result, various scientific societies, including the American Thyroid Association (ATA), European Thyroid Association (ETA) and the Thyroid Society report insufficient evidence and clinical trials on the effectiveness of levothyroxine treatments in these women in terms of pregnancy or neonatal outcomes. These societies mostly refer to a single clinical trial conducted by Negro et al. that reported a lower rate of adverse outcomes in TPO antibody-positive women treated with levothyroxine (18). In spite of this, in another study of infertile women undergoing assisted reproduction technologies, Negro et al. found LT4 treatment was not beneficial (19); neither did Lata et al. report any differences in the incidence of miscarriage among hypothyroid/euthyroid thyroid antibody-positive women (17). Generally, data available are lacking in recommendations for/or against routine levothyroxine therapy during pregnancy in thyroid antibody-positive euthyroid/subclinical hypothyroid women.

The purpose of this population-based study was to identify whether $\mathrm{TPOAb}^{+}$women without overt thyroid dysfunction are affected by higher rates of pregnancy complications and to determine the efficacy of levothyroxine on the outcomes of pregnancy in these women.

\section{Subjects and methods}

\section{Study design and participants}

This study was conducted in two phases, the first of which was a population-based cross sectional study in which 1746 pregnant women, attending prenatal clinics of Shahid Beheshti Medical University, were screened for thyroid dysfunction by collecting data on medical history, clinical examination and measurement of serum concentrations of TSH, T4 (TT4), T-uptake and TPOAb. By excluding those with twin pregnancies $(n=28)$, those diagnosed with hyperthyroidism or overt hypothyroidism and those $\mathrm{TPOAb}^{-}$subclinical hypothyroid women, 134 $\mathrm{TPOAb}^{+}$(euthyroid and subclinical) women and 1092 euthyroid $\mathrm{TPOAb}^{-}$women remained and were invited for the second phase of the study; of these, 1028 and 131 women accepted respectively (Fig. 1). The second phase of this study was a single blind clinical trial conducted on $\mathrm{TPOAb}^{+}$subjects, divided into two groups, group A $(n=65)$, treated with LT4 and group B ( $n=66)$, without treatment; $\mathrm{TPOAb}^{-}$women with normal TSH and FT4 served as the control group (group C); all three groups were followed and adverse outcomes of pregnancy including preterm delivery, miscarriage, placenta abruption, still birth and neonatal admission. Secondary outcomes were placenta abruption, still birth, neonatal admission and neonatal TSH levels were documented. LT4 administration was initiated 4-8 days after the first prenatal visit in group A.

We used the same protocol for intervention as Negro et al. did (18); those in the intervention group received a morning dose of $0.5 \mu \mathrm{g} / \mathrm{kg} /$ day if they had TSH $<1.0 \mu \mathrm{IU} / \mathrm{mL}, 0.75 \mu \mathrm{g} / \mathrm{kg} /$ day for TSH between 1.0 and $2.0 \mu \mathrm{IU} / \mathrm{mL}$, and a $1 \mu \mathrm{g} / \mathrm{kg} /$ day dose for TSH $>2.0 \mu \mathrm{IU} /$ $\mathrm{mL}$ or a TPOAb titer exceeding $1500 \mathrm{IU} / \mathrm{mL}$; dosages were maintained throughout gestation.

Written informed consent was obtained from all participants, and the study was approved by the ethics committee of the Research Institute of Endocrine Sciences (RIES) (approval no: 32ECRIES92/07/23). This study is registered in the Iranian Randomized Clinical Trials Registry (IRCT, code: IRCT2013100114849N1).

\section{Randomization}

Pregnant women, positive for thyroid peroxidase antibodies (TPOAb), with normal TSH and FT4 were randomly divided into two groups. Randomization was performed in blocks of four using a computer-generated list. Physicians, who participated in various phases of 


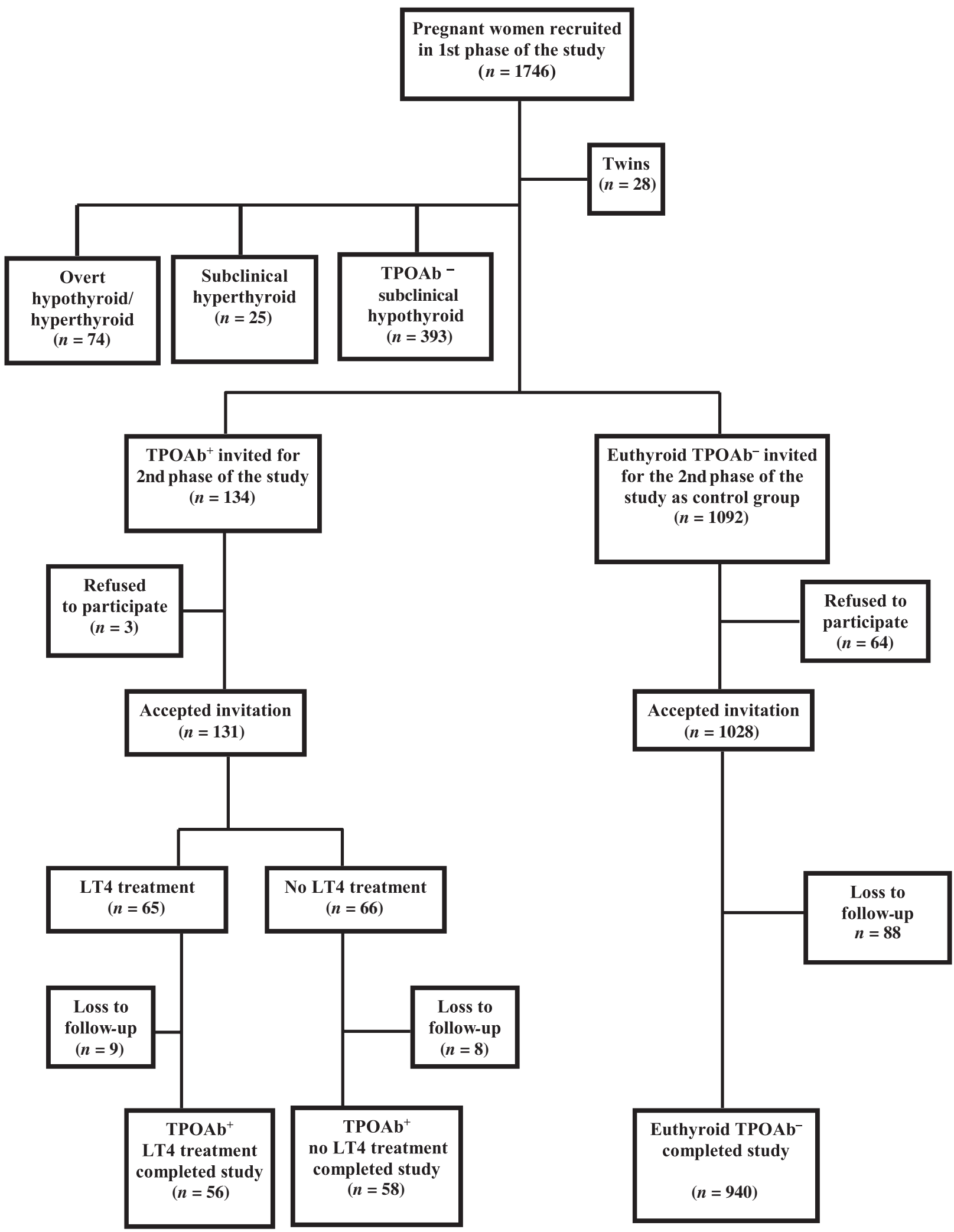

Figure 1

Study flowchart. 
the study, were blinded to grouping of patients; only the health care provider, who did not participate in any phase of the study, was aware of the group the patient was in.

Masking to treatment allocation was not possible; only those in a position to determine pregnancy outcome of mother and neonate were blinded to treatment allocation.

\section{Study procedure}

A comprehensive questionnaire including information on demographic, reproductive, medical and prenatal history was filled out, during face-to-face interviews; a checklist including all potential risk factors, as recommended by the American Thyroid Association (20), was completed for all participants and physical examinations including thyroid, weight, height, systolic and diastolic pressure were conducted; overnight blood samples were collected and after centrifugation were sent to the Research Institute of Endocrine Sciences (RIES) of Shahid Beheshti University of Medical Sciences. Serum concentration of thyroxin (T4), T-uptake, thyrotropin (TSH) and thyroid peroxidase antibody (TPOAb) were measured to determine the thyroid status of participants. As free T4 (FT4) immunoassays may be influenced by pregnancyrelated changes of serum thyroxine-binding globulin and albumin, in a method-specific manner, to assess FT4 status, we used Free Thyroxine Index (FT4I) (21) calculated using the formula: FT4I=T4 $\times \mathrm{T}$-uptake $/ 100$. Three casual morning urine samples $(5-10 \mathrm{~mL})$ for each participant were collected on every other day basis and kept frozen at $-20^{\circ} \mathrm{C}$ until assayed at the end of the study; the median urinary iodine was calculated. Blood samples were collected during the second (20- to 24-weeks gestation) and third (30- to 34-weeks gestation) trimesters; samples were obtained during fasting (before ingestion of LT4 in group A); serum was separated and stored at $-80^{\circ} \mathrm{C}$ till the end of the study for measurement of thyroid hormones. Serum concentrations of neonatal TSH were measured from heel blood samples, 3-5 days after delivery. Gestational age was calculated according to the first day of their last menstrual cycle (LMP) for women with regular cycles and/or ultrasonography for those with irregular cycles or those who could not precisely recall their LMP $(n=66)$.

Women with baseline TSH levels of $0.1-2.5 \mu \mathrm{IU} / \mathrm{mL}$, FT4I $1-4.5$ and TPO $<50 \mathrm{IU} / \mathrm{mL}$ were considered euthyroid $\mathrm{TPO}^{-}$and served as controls. Overt hyperthyroidism was defined as TSH levels $<0.1 \mu \mathrm{IU} / \mathrm{mL}$ and FT4I $>4.5$.
Overt hypothyroidism was defined as TSH $>10 \mu \mathrm{IU} / \mathrm{mL}$ or TSH levels $>2.5 \mu \mathrm{IU} / \mathrm{mL}$ and FT4I $<1$. Subclinical hypothyroidism was defined as normal FT4I (1-4.5), despite elevated TSH $(2.5-10 \mu \mathrm{IU} / \mathrm{mL})$. Subclinical hyperthyroidism was defined as normal FT4I (1-4.5), despite reduced TSH (TSH <0.1). Individuals with TPOAb levels $>50 \mathrm{IU} / \mathrm{mL}$ were considered $\mathrm{TPO}^{+}$.

Using radioimmunoassay (RIA) and immunoradiometric assay (IRMA), T4 and TSH were measured using commercial kits (Izotop Kit, Budapest co, Hungary) and the Gamma-counter (Dream Gamma10, Goyang-si, Gyeonggi-do, South Korea); T-uptake and $\mathrm{TPOAb}$ were measured by the enzyme immunoassay (EIA) (Diaplus Kit, San Francisco, CA, USA) and immunoenzymometric assay (IEMA) (Monobind Kit, Costa Mesa, CA, USA) respectively using a calibrated ELISA reader (Sunrise, Tecan Co. Salzburg, Austria). Inter-assay and intra-assay coefficients of variation for T4, T-uptake, TSH and TPOAb were $1.1 \%$ and $3.9 \%, 2.2 \%$ and $4.3 \%$, $1.9 \%$ and $4.7 \%$ and $1.0 \%$ and $1.6 \%$ respectively.

Urinary iodine concentration was measured using a manual method, based on the Sandell-Kolthoff technique (22). The intra-assay (coefficient variation) in three ranges of 3.4, 12.5 and $37.1 \mu \mathrm{g} / \mathrm{L}$ were $8.5,7.2$ and $9.6 \%$ respectively, and inter-assay CVs \% were 9.1, 8.6 and $12.3 \%$ respectively.

\section{Outcomes}

In this study, the primary outcome was preterm delivery, defined as birth before 37-weeks' gestation. Secondary outcomes were placenta abruption, still birth, neonatal admission and neonatal TSH levels. Miscarriage was defined as the loss of an embryo or fetus before the 20th week of pregnancy. Placental abruption was defined as separation of the placenta from the wall of the uterus during pregnancy. Still birth was defined as birth of an infant that died in the mother's uterus, after 20 weeks of gestation. Newborn admission was defined as the admission of a neonate to the neonatal unit, mainly due to fetal distress or icterus.

\section{Statistical analysis}

Sample size was calculated for intention for treatment analysis with superiority assumption (in terms of primary outcome). A sample of 130 (65 subjects per group) was needed to detect a reduction in preterm delivery of $10 \%$ in the intervention group, compared to $30 \%$ in the control 
ฉ্

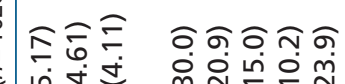

产

๑ิ

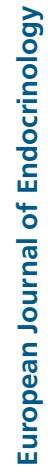

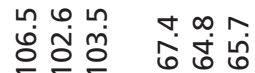

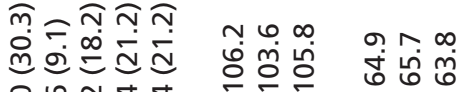

产完管空

ํํำ

ปั

สุิ ลุษ

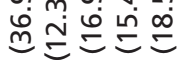

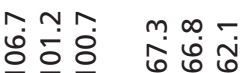

ம더엉

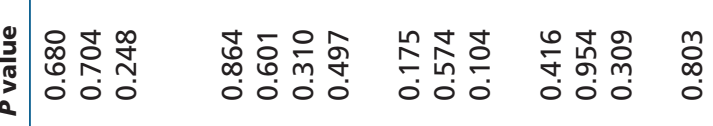

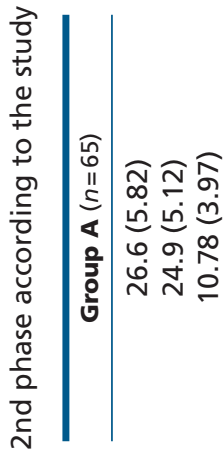

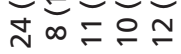

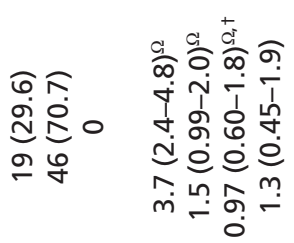

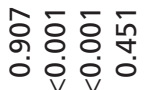
$\stackrel{\infty}{\circ} \stackrel{\infty}{+}$

¿d d

n m

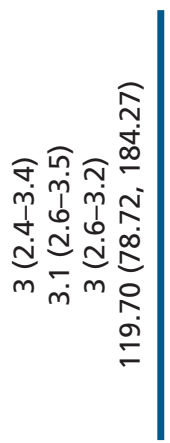

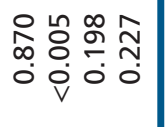

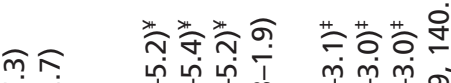

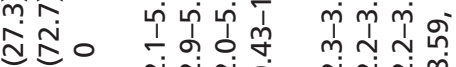

dِ d d

$\stackrel{\infty}{\sim} \stackrel{\infty}{\sim} \stackrel{\infty}{\sim} \stackrel{\infty}{\sim}$

$\stackrel{+}{Ð}$

ঔ

政

要

语要

号谜

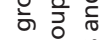

을 के 음

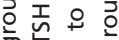

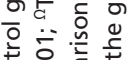

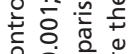

uv $\begin{gathered}0 \\ \text { u }\end{gathered}$

의의

윽 옹

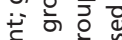

웅

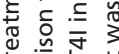

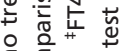

c हो

$3 . \leq 00$

है

ว่

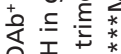

안돈

के iे

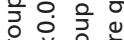

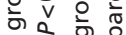

过的施

$\exists$

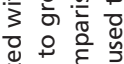

尊

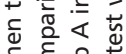

है है 웡ㅊ

3 단

定实.

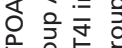

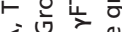

住.

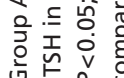


group, with a two-sided 5\% significance level, a power of $80 \%$ and a loss to follow-up of $10 \%$. The calculated sample size for the first phase of the study was 1600 , among these, 122 euthyroid/subclinical TPOAb ${ }^{+}$women were detected who did not provide us enough cases in each study group; hence, recruitment of pregnant women was continued until we had 1746 subjects, which resulted in 131 women with TPOAb+.

All analyses were by intention to treat. No participants were excluded from the primary intention-to-treat analysis for protocol violations. The primary outcome was calculated as event numbers and percentages by treatment allocation. Effect measures (relative risks (RRs)) were calculated with 95\% CIs, with expectant management as the reference group. There was no imputation for missing outcomes. Participants with missing data were excluded from calculation. Number needed to treat (NNT) was defined as the numeric cohort of patients who need to be treated to prevent the occurrence of primary outcome.

Continuous variables were checked for normality using the one-sample Kolmogorov-Smirnov test; categorical variables are expressed as percentages and were compared using Pearson's $\chi^{2}$ test. Continuous variables with normal distribution were compared between the two groups, using $t$-test and are expressed as mean \pm S.D. Non-normal distributed variables, expressed as median (interquartiles), were compared, using Mann-Whitney test. The one-way analysis of variance (ANOVA) was used to determine whether there were any differences between the means of gestational age, birth weight, birth height and birth head circumference in the three study groups. An ANOVA with repeated measure was used to compare means of the three groups, for which participants were measured three times to see if there were any changes in TSH and FTI. The effect of treatment on mediated variable (preterm delivery) was estimated using mediation analysis (23). Statistical analysis was performed using SPSS software, version 18.

\section{Results}

Mean \pm S.D.s of age and gestational age of the women were $26.7 \pm 5.14$ years and $11.4 \pm 4.2$ weeks respectively; 1204 (75.3\%) women were <14 weeks pregnant and 396 (24.7) were between 14 and 20 weeks. Mean \pm s.D. of BMI was $25.3( \pm 7.47) \mathrm{kg} / \mathrm{m}^{2}$. Of pregnant women, $636(36.4 \%)$ were primigravida and 1110 (63.6\%) multigravida; there was history of infertility in 96 (5.5\%) pregnant women.

Using the predefined classification, after excluding twins ( $n=28), 36.4 \%$ (626) had thyroid disorders, including $0.8 \% \quad(n=14)$ overt hyperthyroidism, $3.5 \%$ $(n=60)$ overt hypothyroidism, 1.5\% ( $n=25)$ subclinical hyperthyroidism, 22.9\% $(n=393) \mathrm{TPOAb}^{-}$subclinical hypothyroidism, $\quad 7.8 \% \quad(n=134) \quad$ euthyroid/subclinical hypothyroidism $\mathrm{TPOAb}^{+}$and $63.6 \%(n=1092)$ were euthyroid $\mathrm{TPOAb}^{-}$; the last two groups (1092 and 134 women) were invited for the 2nd phase of the study, of which 1028 and 131 accepted respectively. Eventually 940 and 114 women completed the study (Fig. 1); there were no significant differences in terms of age, education, parity and gestational age at the initiation of the study between those who completed the study and those who did not.

Characteristics of women who participated in phase 2, based on the study groups (A, B and C) are presented in Table 1. There were no statistically significant differences between demographics, anthropometrics and the reproductive history of study groups; nor were there any significant differences in mean birth weight, head circumference (Table 2) and neonate TSH levels

Table 2 Pregnancy outcomes in study groups.

\begin{tabular}{|c|c|c|c|}
\hline Pregnancy adverse outcomes & Group A $(n=56)$ & Group B $(n=58)$ & Group C $(n=940)$ \\
\hline Miscarriage*, n (\%) & $2(3.6)$ & $2(3.4)$ & $40(4.3)$ \\
\hline Placental abruption*, $n(\%)$ & 0 & 0 & $5(0.5)$ \\
\hline Preterm delivery*, $n(\%)$ & $4(7.1)^{\dagger}$ & $14(23.7)^{¥}$ & $53(5.6)$ \\
\hline Still birth*, $n(\%)$ & 0 & 0 & $2(0.2)$ \\
\hline Neonatal admission*, $n(\%)$ & $2(3.6)^{\dagger}$ & $12(20.7)^{¥}$ & $75(8.0)$ \\
\hline Gestational age**, mean (S.D.) & $39.3(1.3)$ & $38.4( \pm 1.7)$ & $39.4( \pm 1.4)$ \\
\hline Birth weight**, mean (s.D.) & $3139.1( \pm 287.6)$ & $3127.7( \pm 523.5)$ & $3236.6( \pm 448.8)$ \\
\hline Birth height**, mean (s.D.) & $49.5( \pm 1.7)$ & $50.3( \pm 1.5)$ & $50.1( \pm 2.3)$ \\
\hline Birth head circumference**, mean (s.D.) & $34.5( \pm 1.1)$ & $34.9( \pm 1.4)$ & $34.7( \pm 1.6)$ \\
\hline
\end{tabular}

Group A, TPOAb+ women treated with LT4; group B, TPOAb+ women no treatment; group C, control group.

${ }^{\dagger}$ Group A vs group $B ; P<0.05 ;{ }^{\ddagger}$ group B vs group $C ; P<0.005 ;{ }^{*} \chi^{2}$ test was used to compare groups; **ANOVA test was used to compare groups. Miscarriage, loss of an embryo or fetus before the 20th week of pregnancy; Placental abruption, separation of the placenta from the wall of the uterine during pregnancy; Preterm delivery, birth before 37 weeks gestation; Still birth, birth of an infant that died in the mother uterine after 20 weeks of gestation; Newborn admission, admission of neonate to neonatal unit mainly due to fetal distress or icterus. 
between the study groups (Table 1). Neither was there any statistically significant correlation of neonatal TSH with first, second and third trimester maternal TSH values, in any of the study groups.

The medians (interquartiles) of urine iodine in groups A, B and C were 84.52 (58.51, 137.23), 104.78 (78.59, $140.24)$ and $119.70(78.72,184,27) \mu \mathrm{g} / \mathrm{L}$ respectively, indicating no significant difference between these groups (Table 1).

Figure 2 shows FT4I (2-A) and TSH values (2-B) of study groups throughout the entire gestation period (1st, 2nd and 3rd measurement); medians (interquartiles) FT4I in group A in the 1st, 2nd and 3rd trimesters were 2.7 (2.3-3.4), 3.1 (2.7-3.7) and 2.9 (2.5-3.1) respectively. Although the first TSH value in group A was not significantly different from that in group B ( $P=0.841$, median (interquartiles): $3.7(2.4-4.8)$ and $3.2(2.1-5.2) \mu \mathrm{IU} / \mathrm{mL}$ respectively), in the 2nd and 3rd trimesters, it was significantly higher in group B, compared to group A $(P<0.001,3.9(2.9-5.4)$ vs
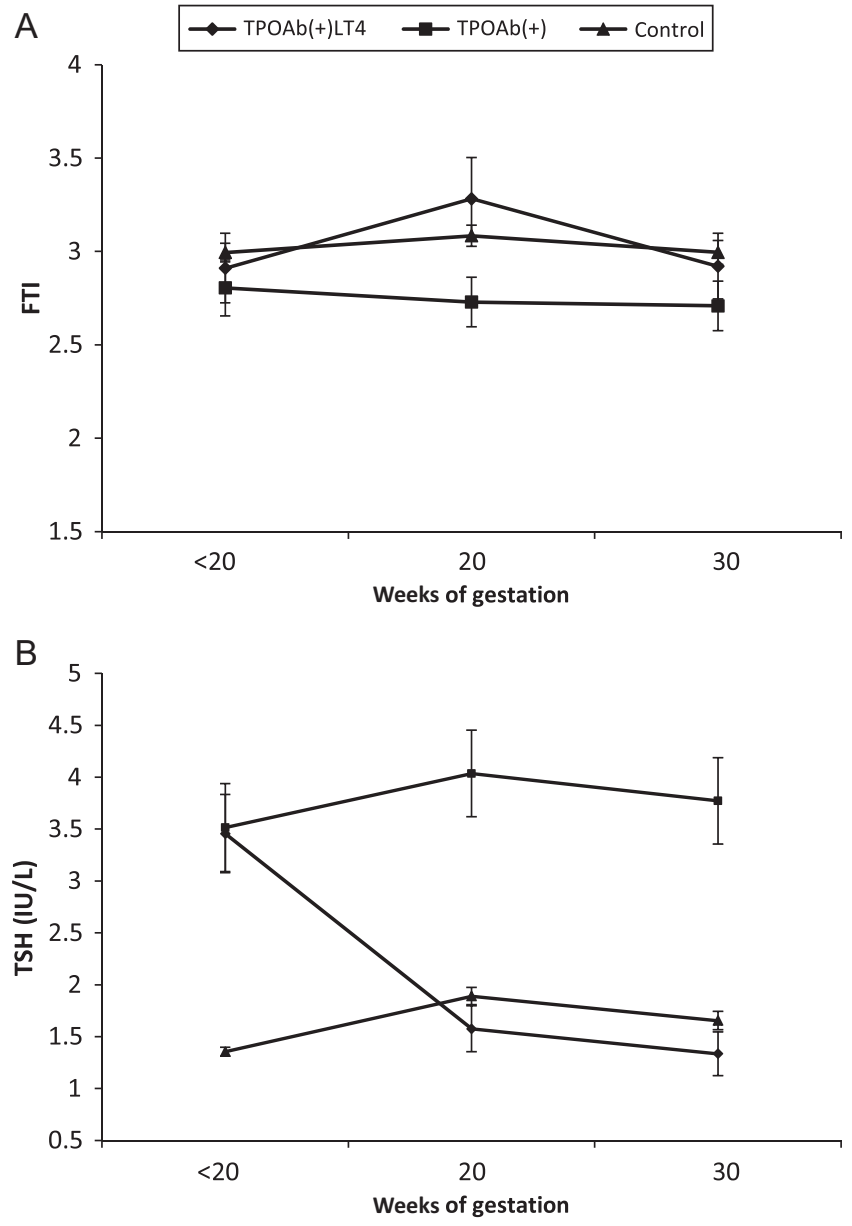

Figure 2

FT4I (2A) and TSH (2B) values during pregnancy.
Table 3 TSH levels in study groups during pregnancy.

\begin{tabular}{|c|c|c|c|}
\hline TSH levels & Group A & Group B & Group C \\
\hline \multicolumn{4}{|c|}{ TSH, 1st visit ( $\mu \mathrm{IU} / \mathrm{mL})(\%)$} \\
\hline$<2.5$ & 30.8 & 40.9 & 100.0 \\
\hline $2.5-5$ & 49.2 & 28.8 & 0.0 \\
\hline $5-10$ & 20.0 & 30.3 & 0.0 \\
\hline \multicolumn{4}{|c|}{ TSH, 2nd trimester $(\mu \mathrm{IU} / \mathrm{mL})(\%)$} \\
\hline$<2.5$ & 81.5 & 19.7 & 76.4 \\
\hline $2.5-5$ & 18.5 & 40.9 & 23.6 \\
\hline $5-10$ & 0.0 & 39.4 & 0 \\
\hline \multicolumn{4}{|c|}{$\mathrm{TSH}, 3$ rd trimester $(\mu \mathrm{IU} / \mathrm{mL})(\%)$} \\
\hline$<2.5$ & 87.7 & 25.8 & 85.9 \\
\hline $2.5-5$ & 10.8 & 36.4 & 14.1 \\
\hline $5-10$ & 0.0 & 37.9 & 0.0 \\
\hline
\end{tabular}

Group A, TPOAb+ women treated with LT4; group B, TPOAb ${ }^{+}$women with no treatment; group $C$, control group.

$1.5(0.99-2.0)$ and $3.4(2.0-5.2)$ vs $0.97(0.60-1.8) \mu \mathrm{IU} / \mathrm{mL}$ respectively) (Table 1). Table 3 shows the percentages of women with TSH values $<2.5,2.5-5$ and $5-10 \mu \mathrm{IU} / \mathrm{mL}$ in each trimester according to the study groups. Although none of the participants in group A had TSH values between 5 and $10 \mu \mathrm{IU} / \mathrm{mL}$ in the 2 nd and 3rd trimesters, $39.4 \%$ and $37.9 \%$ of women in group B had TSH values within this range in these trimesters respectively (Table 3 ).

The rates of preterm deliveries in groups $\mathrm{A}$ and $\mathrm{C}$ were lower than those of group B ( $\mathrm{RR}=0.30,95 \% \mathrm{CI}$ : 0.1-0.85, $P=0.0229)$ and (RR=0.23, 95\% CI: $0.14-0.40, P<0.001)$ respectively. There was no significant difference in the rates of preterm labor between groups $\mathrm{A}$ and $\mathrm{C}(\mathrm{RR}=0.79$,

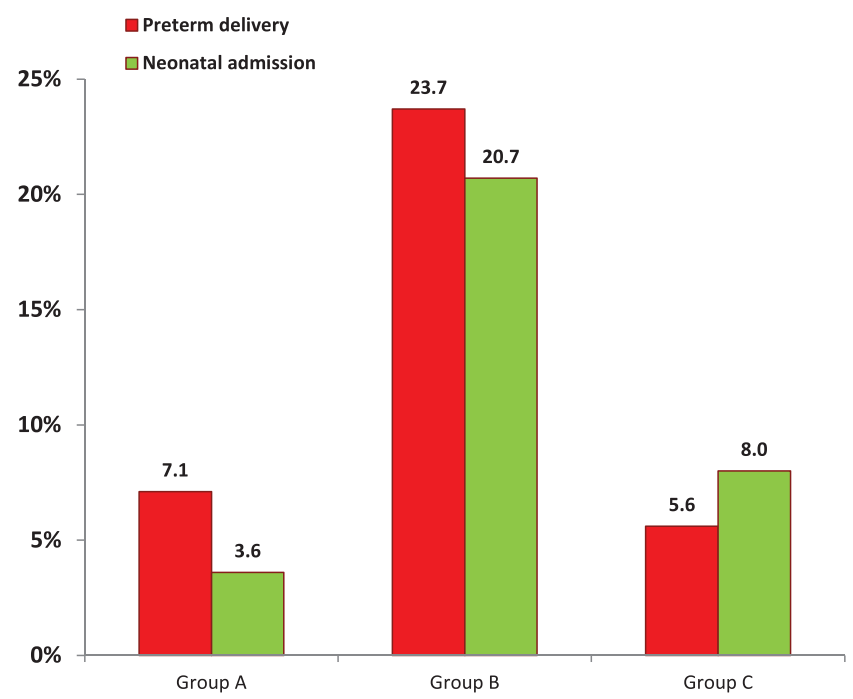

Figure 3

Preterm delivery and neonatal admission among study groups. A full colour version of this figure is available at http://dx.doi. org/10.1530/EJE-16-0548. 
95\% CI: 0.30-2.09, $P=0.64$ ) (Fig. 3 and Table 2). The number needed to treat (NNT) for the preterm birth was 5.9 (95\% CI: 3.33-25.16).

The rates of neonatal admission in groups $\mathrm{A}$ and $\mathrm{C}$ were significantly lower than those in group $\mathrm{B}((P=0.005$, $\mathrm{RR}=0.17,95 \% \mathrm{CI}: 0.04-0.73)$ and $(P=0.001, \mathrm{RR}=0.38$, 95\% CI: 0.22-0.66) respectively) (Fig. 3 and Table 2). The number needed to treat (NNT) for neonatal admission was 5.84 (95\% CI: 3.48-18.23). In addition, by adjusting the effect of intervention on NICU for preterm status, the risk of neonatal admission in term neonates of the 'no LT4' group was twice that of the LT4 group $(P=0.3, \mathrm{RR}=0.42$, 95\% CI: 0.072-2.38), although it was not significant as the majority of admissions to NICU were preterm. Mediation analysis demonstrated that $50 \%$ of the decrease in the risk of neonatal admission due to treatment was mediated via the decrease in premature delivery after LT4 treatment $\left(\mathrm{RR}_{\mathrm{AC}} / \mathrm{RR}_{\mathrm{AB}}=\log (0.42) / \log (0.17)=0.5\right)$.

There were no significant differences in mean birth weight, head circumference and neonate TSH levels between the study groups (Tables 1 and 2); neither were there any significant correlations between the first, second and third trimester maternal TSH values with neonatal TSH, in any of the study groups. Two cases in group A stopped taking LT4 and none of group B or C took LT4, excluding these two cases did not change the results significantly.

Subgroup analysis of data, based on cut-off values of $4 \mu \mathrm{IU} / \mathrm{mL}$ for $\mathrm{TSH}$ and $150 \mu \mathrm{g} / \mathrm{L}$ for urinary iodine is presented in Tables 4 and 5; using these cut-off values demonstrated no significant differences in terms of preterm delivery or neonatal admission between those women in groups A and B with TSH level of $<4 \mu \mathrm{IU} / \mathrm{mL}$, but there were significant differences in preterm delivery and neonatal admission of women in groups $\mathrm{A}$ and $\mathrm{B}$, who had baseline TSH values of $\geq 4 \mu \mathrm{IU} / \mathrm{mL}$ (5.3\% vs $29.4 \%$; $P=0.01$ ) and (0 vs 29.4\%, $P<0.001$ ) respectively. Preterm delivery was observed in 13 (28.2\%) and 1 (8.3\%) women in group B with urinary iodine $<150 \mu \mathrm{g} / \mathrm{L}$ and $\geq 150 \mu \mathrm{g} / \mathrm{L}$ respectively, a difference not statistically significant $(P=0.26)$.

\section{Discussion}

This study revealed that administration of levothyroxine in $\mathrm{TPOAb}^{+}$pregnant women with no overt thyroid dysfunction can lead to $70 \%$ and $83 \%$ decrease in preterm delivery and neonatal hospital admissions respectively. We found that by treating $5.9 \mathrm{TPOAb}^{+}$pregnant women with levothyroxine, one preterm delivery could be prevented. The beneficiary effect of LT4 treatment was mainly observed among $\mathrm{TPOAb}^{+}$women with $\mathrm{TSH} \geq 4 \mu \mathrm{IU} /$ $\mathrm{mL}$; in women receiving LT4, preterm delivery was $5.3 \%$, whereas it was $29.4 \%$ among those without the treatment $(P=0.01)$.

It is well known that overt thyroid dysfunction is associated with pregnancy complications $(3,11)$. One meta-analysis demonstrated a 1.19- and 1.24-fold increase in risk of preterm delivery in pregnant women with overt hypothyroidism and hyperthyroidism, compared to the reference group respectively (11). However, the association between $\mathrm{TPOAb}^{+}$in euthyroid/subclinical pregnant women and adverse pregnancy outcomes is not yet fully understood, and the underlying mechanisms involved have not been clarified (24). Thyroid autoantibodies may exert their adverse effects on pregnancy outcomes in both a TSH-dependent and a TSH-independent manner. The alteration in TSH/T4 levels has a clear antibody-dependent component; it has been shown that baseline TSH levels of pregnant women were significantly higher in $\mathrm{TPO}^{+}$ women than in TPO negative women, whereas they were well within the euthyroid range (25). It seems that women who are positive for thyroid antibodies before pregnancy may have subtle preexisting thyroid dysfunction that could possibly worsen during pregnancy $(26,27)$. Besides these women may not be able to adequately respond to their demand for the augmented synthesis of thyroid

Table 4 Pregnancy outcomes in study groups based on cut-off values of $4 \mu \mathrm{IU} / \mathrm{mL}$ for TSH.

\begin{tabular}{|c|c|c|c|c|c|c|c|c|c|}
\hline \multirow[b]{3}{*}{ Adverse pregnancy outcomes } & \multicolumn{9}{|c|}{ TSH value } \\
\hline & \multicolumn{3}{|c|}{$<4 \mu \mathrm{lU} / \mathrm{mL}$} & \multicolumn{3}{|c|}{$\geq 4 \mu \mathrm{IU} / \mathrm{mL}$} & \multirow{2}{*}{\multicolumn{3}{|c|}{ Controls }} \\
\hline & $\begin{array}{c}\text { Group A } \\
(n=18)\end{array}$ & $\begin{array}{c}\text { Group B } \\
(n=24)\end{array}$ & $P$ value & $\begin{array}{c}\text { Group A } \\
(n=38)\end{array}$ & $\begin{array}{c}\text { Group B } \\
(n=34)\end{array}$ & $P$ value & & & \\
\hline Preterm delivery, $n(\%)$ & $2(11.1)$ & $4(16.7)$ & 0.69 & $2(5.3)$ & $10(29.4)$ & 0.01 & - & - & - \\
\hline Neonatal admission, $n(\%)$ & $2(11.1)$ & $2(8.3)$ & 0.99 & $0(0)$ & $10(29.4)$ & $<0.001 *$ & - & - & - \\
\hline
\end{tabular}

Group A, TPOAb+ women treated with LT4; group B, TPOAb+ women with no treatment; group C, control group. $\chi^{2}$ test was used to compare groups. *Fisher's exact test was used to compare groups.

Preterm delivery, birth before 37 weeks' gestation; Neonatal admission, admission of neonate to neonatal unit mainly due to fetal distress or icterus. 
Table 5 Pregnancy outcomes in study groups based on cut-off values of $150 \mu \mathrm{g} / \mathrm{L}$ for urinary iodine.

\begin{tabular}{|c|c|c|c|c|c|c|c|c|c|}
\hline \multirow[b]{3}{*}{ Adverse pregnancy outcomes } & \multicolumn{9}{|c|}{ Urinary iodine } \\
\hline & \multicolumn{3}{|c|}{ Group A } & \multicolumn{3}{|c|}{ Group B } & \multicolumn{3}{|c|}{ Controls } \\
\hline & $\begin{array}{c}<150 \mu \mathrm{g} / \mathrm{L} \\
(n=37)\end{array}$ & $\begin{array}{c}\geq 150 \mu \mathrm{g} / \mathrm{L} \\
(n=19)\end{array}$ & $\begin{array}{c}P \\
\text { value* }\end{array}$ & $\begin{array}{c}<150 \mu \mathrm{g} / \mathrm{L} \\
(n=46)\end{array}$ & $\begin{array}{c}\geq 150 \mu \mathrm{g} / \mathrm{L} \\
\quad(n=12)\end{array}$ & $\begin{array}{c}P \\
\text { value* }\end{array}$ & $\begin{array}{l}<150 \mu \mathrm{g} / \mathrm{L} \\
(n=540)\end{array}$ & $\begin{array}{c}\geq 150 \mu \mathrm{g} / \mathrm{L} \\
(n=400)\end{array}$ & $\begin{array}{c}P \\
\text { value* }\end{array}$ \\
\hline Preterm delivery, $n(\%)$ & $3(8.1)$ & $1(5.3)$ & 0.99 & $13(28.2)$ & $1(8.3)$ & 0.26 & $28(5.2)$ & $25(6.3)$ & 0.48 \\
\hline Neonatal admission, $n(\%)$ & $2(5.4)$ & $0(0)$ & 0.54 & $9(19.6)$ & $3(25.0)$ & 0.70 & $48(8.9)$ & $27(6.8)$ & 0.23 \\
\hline
\end{tabular}

Group A, TPOAb+ women treated with LT4; group B, TPOAb+ women with no treatment; group C, control group. $\chi^{2}$ test was used to compare groups. *Fisher's exact test was used to compare groups.

Preterm delivery, birth before 37 weeks' gestation; Neonatal admission, admission of neonate to neonatal unit mainly due to fetal distress or icterus.

hormones required during pregnancy (28); as a result subclinical or overt hypothyroidism may occur during pregnancy $(26,27,28)$. Thyroid autoantibodies may exert their effect in a TSH-independent manner that includes quantitative and qualitative changes in the profile of endometrial T cells with reduced secretion of IL- 4 and IL-10 along with hypersecretion of interferon $\gamma$ (29). Besides the hyperactivity and increased migration of cytotoxic natural killer cells that alter the immune and hormonal response of the uterus are up to $40 \%$ more common in women with thyroid autoimmunity (29). It has also been shown that thyroid autoimmunity may represent a marker of a generalized autoimmune imbalance that could result in dysregulated activity of the immune system at the fetalmaternal interface $(14,30)$.

Despite the known association between overt thyroid dysfunction and preterm labor, data on the relationship between subclinical thyroid dysfunction and thyroid autoimmunity with preterm labor are inconsistent. Although one meta-analysis, based on fourteen cohort studies and one case control study, demonstrated no significant increase in odds ratio of preterm labor in women with subclinical hypothyroidism (11), another reported a pooled odds ratio of $1.30(1.05-1.60)$ for preterm delivery in subclinical hypothyroidism, compared to women with euthyroidism, using a random effects model (10). It is assumed that thyroid autoimmunity may be associated with an increased risk of preterm labor due to an inadequate response to the additional demand for thyroid hormones required during pregnancy (28) or because of dysregulation of local inflammatory processes involved in the cytokine networks of the local placental-decidual environment $(31,32,33,34,35)$, dysregulation, which per se can have a direct adverse effect on placental or fetal development $(18,28)$. Besides lack of vitamin D has been suggested as a predisposing factor to autoimmune diseases and is known to be reduced in patients with thyroid autoimmunity (36); in turn, its deficiency is also linked to pregnancy loss, suggesting a potential interplay with thyroid autoimmunity in the context of adverse pregnancy outcomes (37). Some studies, in agreement with ours, have reported a 2- to 3-fold increase in preterm delivery in euthyroid/subclinical $\mathrm{TPOAb}^{+}$pregnant women $(6,8$, $38,39,40)$, whereas others did not report this association $(15,41)$. A meta-analysis by Van den Boogaard et al. also showed that the presence of thyroid antibodies has been associated with a 1.9-fold increase in risk of premature birth (42); these differences in results might be due to differences in study design, age differences in study groups, BMI, ethnicities, iodine status and so forth. For instance, in some studies, women with antibodies were older than those without the antibodies; hence, older age, per se, may explain the increased rate of fetal loss (43). Studies on the effectiveness of levothyroxine treatment on adverse feto-maternal outcomes have documented inconsistent results. Negro et al., in agreement with results of the current study, found that $\mathrm{TPOAb}^{+}$pregnant women (euthyroid and subclinical hypothyroidism) are associated with an increased risk of preterm delivery, and treatment with levothyroxine can reduce the risk (18); Lata et al., however, reported no effect of LT4 treatment on miscarriage among women with hypothyroidism and euthyroid $\mathrm{TPOAb}^{+}$women (17).

Thyroid autoantibodies are believed to increase early pregnancy loss through changes in the profile of endometrial $\mathrm{T}$ cells, hyperactivity and increased migration of cytotoxic natural killer cells, affecting zona pellucida, human chorionic gonadotropin receptors and other placental antigens $(44,45,46)$. Nevertheless, data regarding the miscarriage consequence of thyroid autoimmunity are inconsistent; despite some studies reporting a positive association between thyroid immunity and rate of miscarriage $(7,47,48,49,50,51,52,53,54)$; others found no association between the presence of TPO antibodies and miscarriage $(9,55,56,57)$. We observed neither increase in rate of miscarriage among $\mathrm{TPOAb}^{+}$ 
women nor a positive effect of LT4 treatment on reducing the rates of miscarriages; however, this is mainly due to the lack of LT4 administration in the very early stages of pregnancy, as the majority of miscarriages occur before 8 weeks of gestation (64.3\% of women in our study had not started LT4 by the 8th week of gestation). Timing of treatment initiation is critical as it seems that normal thyroid function is primarily important in early pregnancy to maintain normal placental development and avoid miscarriages (18). Besides differences in gestational age of participants, age, BMI, ethnicity and iodine status of various populations also differ, which may partly explain the various associations between thyroid immunity and miscarriage. The present study was conducted in Iran, an iodine sufficient area according to the national surveillance study among Iranian students (58); however, we found that iodine sufficiency among students could not guarantee iodine sufficiency in pregnant women, and although the median level of urinary iodine was $>100 \mu \mathrm{g} / \mathrm{L}$, it was still much lower than the level recommended for pregnant women $(150 \mu \mathrm{g} / \mathrm{L})$.

Subgroup analysis of our data set, stratifying the analyses according to TSH value of $4 \mu \mathrm{IU} / \mathrm{mL}$, showed that the beneficial effect of LT4 treatment on our primary outcomes was predominantly present in women with TSH $>4 \mu \mathrm{IU} / \mathrm{mL}$. It seems that the TSH cut-off value of $2.5 \mu \mathrm{IU} /$ $\mathrm{mL}$ suggested by the American Thyroid Association (ATA) and European Thyroid Association (ETA) need to be revised, as it may result in an over diagnosis of subclinical hypothyroidism among pregnant women; the reference values for TSH in various populations, reported to be much higher than $2.5 \mu \mathrm{IU} / \mathrm{mL}$, range from 2.63 to $4.68 \mu \mathrm{IU} / \mathrm{mL}$ (59). In our study, apparently even using a cut-off value of $4 \mu \mathrm{IU} / \mathrm{mL}$, LT4 treatment did not improve pregnancy outcomes in euthyroid $\mathrm{TPOAb}^{+}$women, a finding similar to that of a recent RCT documented by Negro et al.; in which, however, they used a threshold of $2.5 \mu \mathrm{IU} / \mathrm{mL}$ for identification of euthyroid women (60).

Regarding strengths and limitations of the present study, this is the second population-based randomized clinical trial, demonstrating the benefits of LT4 administration on adverse pregnancy outcomes in terms of preterm delivery; in addition, it showed decrease in neonatal admissions and improved maternal thyroid status throughout gestation; it is noteworthy that the iodine status of participants in this investigation has been assessed for the first time simultaneously with their thyroid hormonal assessment. The results of this study should be extrapolated considering the following limitations: First, despite efforts for recruitment of pregnant women in the very early stages of pregnancy for administration of LT4 to those qualified for treatment, untimely referral of some women led to the initiation of treatment at the end of the first trimester, which could interrupt the precise assessment of LT4 effects on miscarriage; as a result, this negative association should be interpreted with caution as the study is underpowered to consider miscarriage as an outcome. Second, we did not use our local trimester-specific cut-off values for TSH and FT4I (21), as these values were introduced after the initiation of the present study. Third, sample size of this study did not allow subgroup analysis using TSH cut-off value of $2.5 \mu \mathrm{IU} / \mathrm{mL}$ for comparison for euthyroid and subclinical hypothyroid $\mathrm{TPOAb}^{+}$subgroups. Fourth, the number of samples was inadequate to examine other rare pregnancy complications, e.g. preeclampsia, stillbirth, etc. Fifth, lack of awareness regarding some other risk factors of miscarriage and premature delivery could influence the results of this study, although the randomized allocation of study participants minimizes this effect. Sixth, as the casual urine iodine values did not reflect iodine status of an individual (due to major day-to-day variability of urinary iodine excretion (61)), the subgroup analysis according to the urinary iodine's concentration needed to be interpreted with caution.

\section{Conclusions}

The results of the study showed that replacement therapy with levothyroxine in $\mathrm{TPOAb}^{+}$pregnant women with normal FT4 improves pregnancy outcomes and is beneficial in reducing preterm delivery and neonatal admissions, a beneficial effect, however, mainly present in women with TSH $>4 \mu \mathrm{IU} / \mathrm{mL}$. Larger randomized clinical trials conducted in various geographic regions with sufficient sample sizes and different iodine and TSH statuses are critically needed to investigate whether LT4 treatment benefits in TPOAb-positive women are dependent on TSH concentrations at initiation.

\section{Declaration of interest}

The authors declare that there is no conflict of interest that could be perceived as prejudicing the impartiality of the research reported.

\section{Funding}

This research did not receive any specific grant from any funding agency in the public, commercial or not-for-profit sector. 


\section{Author contribution statement}

S N contributed to study design, execution, analysis, manuscript drafting and critical discussion. F R T contributed to study design, analysis, manuscript drafting and critical discussion. M S contributed to study design and manuscript drafting. M T contributed to laboratory testing and manuscript drafting. $\mathrm{H} \mathrm{A}$ contributed to study design and analysis. F A contributed to study design, execution and manuscript drafting.

\section{Acknowledgements}

The authors are indebted to each of the study participants for the substantial time and effort contributed to this study. They would like to acknowledge N Shiva for critical editing of English grammar and syntax of the manuscript.

\section{References}

1 Chen L \& Hu R. Thyroid autoimmunity and miscarriage: a metaanalysis. Clinical Endocrinology 201174 513-519. (doi:10.1111/j.13652265.2010.03974.x)

2 Cignini P, Cafa EV, Giorlandino C, Capriglione S, Spata A \& Dugo N. Thyroid physiology and common diseases in pregnancy: review of literature. Journal of Perinatal Medicine 20126 64-71.

3 Mannisto T, Mendola P, Grewal J, Xie Y, Chen Z \& Laughon SK. Thyroid diseases and adverse pregnancy outcomes in a contemporary US cohort. Journal of Clinical Endocrinology and Metabolism 201398 2725-2733. (doi:10.1210/jc.2012-4233)

4 Casey BM, Dashe JS, Wells CE, McIntire DD, Byrd W, Leveno KJ \& Cunningham FG. Subclinical hypothyroidism and pregnancy outcomes. Obstetrics and Gynecology 2005105 239-245. (doi:10.1097/01.AOG.0000152345.99421.22)

5 Glinoer D, Riahi M, Grun JP \& Kinthaert J. Risk of subclinical hypothyroidism in pregnant women with asymptomatic autoimmune thyroid disorders. Journal of Clinical Endocrinology and Metabolism 199479 197-204. (doi:10.1210/jcem.79.1. 8027226)

6 Karakosta P, Alegakis D, Georgiou V, Roumeliotaki T, Fthenou E, Vassilaki M, Boumpas D, Castanas E, Kogevinas M \& Chatzi L. Thyroid dysfunction and autoantibodies in early pregnancy are associated with increased risk of gestational diabetes and adverse birth outcomes. Journal of Clinical Endocrinology and Metabolism 2012 97 4464-4472. (doi:10.1210/jc.2012-2540)

7 Negro R, Schwartz A, Gismondi R, Tinelli A, Mangieri T \& Stagnaro-Green A. Thyroid antibody positivity in the first trimester of pregnancy is associated with negative pregnancy outcomes. Journal of Clinical Endocrinology and Metabolism 201196 E920-E924. (doi:10.1210/jc.2011-0026)

8 Cleary-Goldman J, Malone FD, Lambert-Messerlian G, Sullivan L, Canick J, Porter TF, Luthy D, Gross S, Bianchi DW $\&$ D'Alton ME. Maternal thyroid hypofunction and pregnancy outcome. Obstetrics and Gynecology 2008112 85-92. (doi:10.1097/ AOG.0b013e3181788dd7)

9 Muller AF, Verhoeff A, Mantel MJ \& Berghout A. Thyroid autoimmunity and abortion: a prospective study in women undergoing in vitro fertilization. Fertility and Sterility 199971 30-34. (doi:10.1016/S0015-0282(98)00394-X)

10 Chan S \& Boelaert K. Optimal management of hypothyroidism, hypothyroxinaemia and euthyroid TPO antibody positivity preconception and in pregnancy. Clinical Endocrinology (Review) 2015 82 313-326. (doi:10.1111/cen.12605)

11 Sheehan PM, Nankervis A, Araujo Junior E \& Da Silva Costa F. Maternal thyroid disease and preterm birth: systematic review and meta-analysis. Journal of Clinical Endocrinology and Metabolism (MetaAnalysisReview) 2015100 4325-4331. (doi:10.1210/jc.2015-3074)
12 Benhadi N, Wiersinga WM, Reitsma JB, Vrijkotte TG \& Bonsel GJ. Higher maternal TSH levels in pregnancy are associated with increased risk for miscarriage, fetal or neonatal death. European Journal of Endocrinology 2009160 985-991. (doi:10.1530/EJE-08-0953)

13 Stagnaro-Green A. Thyroid antibodies and miscarriage: where are we at a generation later? Journal of Thyroid Research 20112011841949. (doi:10.4061/2011/841949)

14 Thangaratinam S, Tan A, Knox E, Kilby MD, Franklyn J \& Coomarasamy A. Association between thyroid autoantibodies and miscarriage and preterm birth: meta-analysis of evidence. BMJ 2011 342 d2616. (doi:10.1136/bmj.d2616)

15 Ashoor G, Rotas M, Maiz N, Kametas NA \& Nicolaides KH. Maternal thyroid function at 11-13 weeks of gestation in women with hypothyroidism treated by thyroxine. Fetal Diagnosis and Therapy 201028 22-27. (doi:10.1159/000314906)

16 Korevaar TI, Schalekamp-Timmermans S, de Rijke YB, Visser WE, Visser W, de Muinck Keizer-Schrama SM, Hofman A, Ross HA, Hooijkaas H, Tiemeier $\mathrm{H}$ et al. Hypothyroxinemia and TPOantibody positivity are risk factors for premature delivery: the generation R study. Journal of Clinical Endocrinology and Metabolism (Research Support, Non-U.S. Gov't) $2013984382-4390$. (doi:10.1210/jc.2013-2855)

17 Lata K, Dutta P, Sridhar S, Rohilla M, Srinivasan A, Prashad GR, Shah VN \& Bhansali A. Thyroid autoimmunity and obstetric outcomes in women with recurrent miscarriage: a case-control study. Endocrine Connections 20132 118-124. (doi:10.1530/ EC-13-0012)

18 Negro R, Formoso G, Mangieri T, Pezzarossa A, Dazzi D \& Hassan H. Levothyroxine treatment in euthyroid pregnant women with autoimmune thyroid disease: effects on obstetrical complications. Journal of Clinical Endocrinology and Metabolism 200691 2587-2591. (doi:10.1210/jc.2005-1603)

19 Negro R, Mangieri T, Coppola L, Presicce G, Casavola EC, Gismondi R, Locorotondo G, Caroli P, Pezzarossa A, Dazzi D et al. Levothyroxine treatment in thyroid peroxidase antibodypositive women undergoing assisted reproduction technologies: a prospective study. Human Reproduction 200520 1529-1533. (doi:10.1093/humrep/deh843)

20 Stagnaro-Green A, Abalovich M, Alexander E, Azizi F, Mestman J, Negro R, Nixon A, Pearce EN, Soldin OP, Sullivan S et al. Guidelines of the American Thyroid Association for the diagnosis and management of thyroid disease during pregnancy and postpartum. Thyroid 201121 1081-1125. (doi:10.1089/thy.2011.0087)

21 Azizi F, Mehran L, Amouzegar A, Delshad H, Tohidi M, Askari S \& Hedayati M. Establishment of the trimester-specific reference range for free thyroxine index. Thyroid 201323 354-359. (doi:10.1089/ thy.2012.0407)

22 ICCIDD. Assessment of Iodine Deficiency Disorders and Monitoring Their Elimination (A Guide for Programme Managers). World Health Organization, 2007.

23 Baron RM \& Kenny DA. The moderator mediator variable distinction in social psychological-research - conceptual, strategic, and statistical considerations. Journal of Personality and Social Psychology 198651 1173-1182. (doi:10.1037/0022-3514.51.6.1173)

24 He X, Wang P, Wang Z, Xu D \& Wang B. Thyroid antibodies and risk of preterm delivery: a meta-analysis of prospective cohort studies. European Journal of Endocrinology 2012167 455-464. (doi:10.1530/ EJE-12-0379)

25 Pearce EN, Oken E, Gillman MW, Lee SL, Magnani B, Platek D $\&$ Braverman LE. Association of first-trimester thyroid function test values with thyroperoxidase antibody status, smoking, and multivitamin use. Endocrine Practices (Multicenter StudyResearch Support, N.I.H., ExtramuralResearch Support, Non-U.S. Gov't) 2008 14 33-39. (doi:10.4158/EP.14.1.33)

26 Banerjee S. Thyroid disorders in pregnancy. Journal of the Association of Physicians of India 201159 (Supplement) 32-34. 
27 Krassas GE, Poppe K \& Glinoer D. Thyroid function and human reproductive health. Endocrine Reviews 201031 702-755. (doi:10.1210/er.2009-0041)

28 Prummel MF \& Wiersinga WM. Thyroid autoimmunity and miscarriage. European Journal of Endocrinology 2004150 751-755. (doi:10.1530/eje.0.1500751)

29 Kim NY, Cho HJ, Kim HY, Yang KM, Ahn HK, Thornton S, Park JC, Beaman K, Gilman-Sachs A \& Kwak-Kim J. Thyroid autoimmunity and its association with cellular and humoral immunity in women with reproductive failures. American Journal of Reproductive Immunology 201165 78-87. (doi:10.1111/j.1600-0897.2010.00911.x)

30 Alexander EK. Autoimmunity: thyroid autoantibodies and pregnancy risk. Nature Reviews Endocrinology 20117 501-502. (doi:10.1038/ nrendo.2011.116)

31 Gleicher N, Barad D \& Weghofer A. Functional autoantibodies, a new paradigm in autoimmunity? Autoimmunity Reviews 2007 42-45. (doi:10.1016/j.autrev.2007.06.001)

32 Kyrklund-Blomberg NB \& Cnattingius S. Preterm birth and maternal smoking: risks related to gestational age and onset of delivery. American Journal of Obstetrics and Gynecology 1998179 1051-1055. (doi:10.1016/S0002-9378(98)70214-5)

33 Nakamura H, Usa T, Motomura M, Ichikawa T, Nakao K, Kawasaki E, Tanaka M, Ishikawa K \& Eguchi K. Prevalence of interrelated autoantibodies in thyroid diseases and autoimmune disorders. Journal of Endocrinological Investigation 200831 861-865. (doi:10.1007/ BF03346432)

34 Scofield RH. Autoantibodies as predictors of disease. Lancet 2004363 1544-1546. (doi:10.1016/S0140-6736(04)16154-0)

35 Weetman AP. Immunity, thyroid function and pregnancy: molecular mechanisms. Nature Reviews Endocrinology 20106 311-318. (doi:10.1038/nrendo.2010.46)

36 Bizzaro G \& Shoenfeld Y. Vitamin D and autoimmune thyroid diseases: facts and unresolved questions. Immunologic Research (Review) 201561 46-52. (doi:10.1007/s12026-014-8579-z)

37 Twig G, Shina A, Amital H \& Shoenfeld Y. Pathogenesis of infertility and recurrent pregnancy loss in thyroid autoimmunity. Journal of Autoimmunity (Review) 201238 J275-J281. (doi:10.1016/j. jaut.2011.11.014)

38 Kumru P, Erdogdu E, Arisoy R, Demirci O, Ozkoral A, Ardic C, Ertekin AA, Erdogan S \& Ozdemir NN. Effect of thyroid dysfunction and autoimmunity on pregnancy outcomes in low risk population. Archives of Gynecology and Obstetrics 2015291 1047-1054. (doi:10.1007/s00404-014-3533-9)

39 Saki F, Dabbaghmanesh MH, Ghaemi SZ, Forouhari S, Omrani GR $\&$ Bakhshayeshkaram M. Thyroid autoimmunity in pregnancy and its influences on maternal and fetal outcome in Iran (a prospective study). Endocrine Research 201540 139-145. (doi:10.3109/07435800.2 014.966384)

40 Stagnaro-Green A. Maternal thyroid disease and preterm delivery. Journal of Clinical Endocrinology and Metabolism 200994 21-25. (doi:10.1210/jc.2008-1288)

41 Tierney K, Delpachitra P, Grossmann M, Onwude J, Sikaris K, Wallace EM, Hamilton EJ \& Tong S. Thyroid function and autoantibody status among women who spontaneously deliver under 35 weeks of gestation. Clinical Endocrinology 200971 892-895. (doi:10.1111/j.1365-2265.2009.03569.x)

42 van den Boogaard E, Vissenberg R, Land JA, van Wely M, van der Post JA, Goddijn M \& Bisschop PH. Significance of (sub) clinical thyroid dysfunction and thyroid autoimmunity before conception and in early pregnancy: a systematic review. Human Reproduction Update 201117 605-619. (doi:10.1093/humupd/ dmr024)

43 Abbassi-Ghanavati M, Casey BM, Spong CY, McIntire DD, Halvorson LM \& Cunningham FG. Pregnancy outcomes in women with thyroid peroxidase antibodies. Obstetrics and Gynecology 2010 116 381-386. (doi:10.1097/AOG.0b013e3181e904e5)
44 Lee YL, Ng HP, Lau KS, Liu WM, O WS, Yeung WS \& Kung AW. Increased fetal abortion rate in autoimmune thyroid disease is related to circulating TPO autoantibodies in an autoimmune thyroiditis animal model. Fertility and Sterility (Research Support, Non-U.S. Gov't) 200991 (Supplement 5) 2104-2109. (doi:10.1016/j. fertnstert.2008.07.1704)

45 Toulis KA, Goulis DG, Venetis CA, Kolibianakis EM, Tarlatzis BC \& Papadimas I. Thyroid autoimmunity and miscarriages: the corpus luteum hypothesis. Medical Hypotheses 200973 1060-1062. (doi:10.1016/j.mehy.2009.05.012)

46 Triggianese P, Perricone C, Conigliaro P, Chimenti MS, Perricone R \& De Carolis C. Peripheral blood natural killer cells and mild thyroid abnormalities in women with reproductive failure. International Journal of Immunopathology and Pharmacology 201629 65-75. (doi:10.1177/0394632015615130)

47 Bagis T, Gokcel A \& Saygili ES. Autoimmune thyroid disease in pregnancy and the postpartum period: relationship to spontaneous abortion. Thyroid 200111 1049-1053. (doi:10.1089/10507250175327 1743)

48 Ghafoor F, Mansoor M, Malik T, Malik MS, Khan AU, Edwards R \& Akhtar W. Role of thyroid peroxidase antibodies in the outcome of pregnancy. Journal of the College of Physicians and Surgeons Pakistan 200616 468-471. (doi:7.2006/JCPSP.468471)

49 Glinoer D, Soto MF, Bourdoux P, Lejeune B, Delange F, Lemone M, Kinthaert J, Robijn C, Grun JP \& de Nayer P. Pregnancy in patients with mild thyroid abnormalities: maternal and neonatal repercussions. Journal of Clinical Endocrinology and Metabolism 199173 421-427. (doi:10.1210/jcem73-2-421)

50 Iijima T, Tada H, Hidaka Y, Mitsuda N, Murata Y \& Amino N. Effects of autoantibodies on the course of pregnancy and fetal growth. Obstetrics and Gynecology 199790 364-369. (doi:10.1016/S00297844(97)00283-4)

51 Liu H, Shan Z, Li C, Mao J, Xie X, Wang W, Fan C, Wang H, Zhang H, Han C et al. Maternal subclinical hypothyroidism, thyroid autoimmunity, and the risk of miscarriage: a prospective cohort study. Thyroid 201424 1642-1649. (doi:10.1089/ thy.2014.0029)

52 Marai I, Carp H, Shai S, Shabo R, Fishman G \& Shoenfeld Y. Autoantibody panel screening in recurrent miscarriages. American Journal of Reproductive Immunology 200451 235-240. (doi:10.1111/ j.1600-0897.2004.00153.x)

53 Nambiar V, Jagtap VS, Sarathi V, Lila AR, Kamalanathan S, Bandgar TR, Menon PS \& Shah NS. Prevalence and impact of thyroid disorders on maternal outcome in asian-Indian pregnant women. Journal of Thyroid Research 20112011429097. (doi:10.4061/2011/429097)

54 Stagnaro-Green A, Roman SH, Cobin RH, el-Harazy E, Alvarez-Marfany M \& Davies TF. Detection of at-risk pregnancy by means of highly sensitive assays for thyroid autoantibodies. JAMA 1990264 1422-1425. (doi:10.1001/ jama.1990.03450110068029)

55 Krassas GE, Perros P \& Kaprara A. Thyroid autoimmunity, infertility and miscarriage. Expert Review of Endocrinology and Metabolism 20083 127-136. (doi:10.1586/17446651.3.2.127)

56 Kutteh WH, Yetman DL, Carr AC, Beck LA \& Scott RT Jr. Increased prevalence of antithyroid antibodies identified in women with recurrent pregnancy loss but not in women undergoing assisted reproduction. Fertility and Sterility $1999 \mathbf{7 1} 843-848$. (doi:10.1016/ S0015-0282(99)00091-6)

57 Rushworth FH, Backos M, Rai R, Chilcott IT, Baxter N \& Regan L. Prospective pregnancy outcome in untreated recurrent miscarriers with thyroid autoantibodies. Human Reproduction 200015 1637-1639. (doi:10.1093/humrep/15.7.1637)

58 Azizi F, Mehran L, Sheikholeslam R, Ordookhani A, Naghavi M, Hedayati M, Padyab M \& Mirmiran P. Sustainability of a 
well-monitored salt iodization program in Iran: marked reduction in goiter prevalence and eventual normalization of urinary iodine concentrations without alteration in iodine content of salt. Journal of Endocrinological Investigation 200831 422-431. (doi:10.1007/ BF03346386)

59 Medici M, Korevaar TI, Visser WE, Visser TJ \& Peeters RP. Thyroid function in pregnancy: what is normal? Clinical Chemistry $2015 \mathbf{6 1}$ 704-713. (doi:10.1373/clinchem.2014.236646)
60 Negro R, Schwartz A \& Stagnaro-Green A. Impact of levothyroxine in miscarriage and preterm delivery rates in first trimester thyroid antibody-positive women with TSH $<2.5 \mathrm{IU} / \mathrm{L}$. Journal of Clinical Endocrinology and Metabolism 201626 jc20161803. (doi:10.1210/ jc.2016-1803)

61 World Health Organization. Urinary iodine concentrations for determining iodine status in populations. WHO/NMH/NHD/ EPG/13.1, 2013.

Received 26 June 2016

Revised version received 18 October 2016

Accepted 22 November 2016 